\title{
The connection between typological complexes of properties of the nervous system, temperaments, and personality types in the professions and sports
}

This article was published in the following Dove Press journal:

Open Access Journal of Sports Medicine

19 May 2015

Number of times this article has been viewed

\author{
Aleksandr K Drozdovski \\ Sports Training Center for Russian \\ Teams, Moscow, Russia
}

\begin{abstract}
Based on experimental studies in education, professions and sports, an attempt was made to combine the following two historically disconnected research directions in the study of the natural human traits into a single coordinate system: Pavlov's theory on the properties of the nervous system, as well as the types of higher nervous activity, and Jung's theory on psychological types. It is noted that Pavlov's school of thought was developed by his followers in Russia within the scientific school of differential psychophysiology, while Yung's theory was developed through the works of well-known American researchers Myers and Keirsey. The spatial model that is presented here rests on the knowledge of the properties of the human nervous system and enables the prediction of psychological characteristics, temperament, and psychological types of individuals belonging to a wide age range.

Keywords: differential psychophysiology, properties of the nervous system, typological complex of properties, psychological properties, temperament and psychological type
\end{abstract}

\section{Introduction}

The 1920s are marked by the following important events in the field of human science: Russian physiologist Ivan Pavlov, who won the Nobel Prize for Physiology or Medicine in 1904, proposed a theory on the properties of the nervous system and the types of higher nervous activity (HNA), while the Swiss psychologist Jung developed the theory of psychological types. For almost a hundred years, these research areas have been developing in parallel. The typological approach to the natural human characteristics based on the theory proposed by Pavlov was developed in Russia within the scientific school of differential psychophysiology (Teplov, Nebylitsyn, Merlin, Gurevich, Ilyin, Golubeva, Kabardov). In psychology, the typological approach based on the teachings of Jung regarding the psychological types was developed by American researchers Mayers and Keirsey. The text description of the personality types (PTs) proposed by Jung's followers is based on rich empirical sources, the application of which can be significantly extended through the combination of the above-mentioned schools of thought into a single coordinate system. In our case, this is implemented through the use of a spatial model of communication between typological complexes (TCs) of properties of the nervous system, temperaments, and psychological types. This "model" reflects the author's experience in scientific and practical work at the Psychological Center for Children and Adolescents, as well as orphanages, schools, gymnasiums, and sports schools of St Petersburg, in the laboratory of experimental psychology, Herzen Pedagogical University (St Petersburg), and at the Sports Training Center for Russian Teams (Moscow), where the author used psychophysiological methods to
Correspondence: Aleksandr K Drozdovski Sports Training Center for Russian Teams, Kazakova street, 18-8, ul Frunze 16 - 104, St Petersburg 196135, Russia Email drozd53@bk.ru 
provide support to members of the Russian National Team in various sports in preparation for the Paralympic Games in Beijing and London, as well as in the preparation of skiers and biathletes for the Paralympic Winter Games in Vancouver and Sochi 2014.

The aim of this copyright long-term studies review is:

1. to introduce the motor express techniques for measuring the person, developed by Professor Ilyin, to experts in the field of sports medicine;

2. to reveal the logic of combining two different scientific approaches in the description of the person (physiology and psychology) on the basis of the original spatial "model," reflecting the relationship between the nervous system properties TC, temperament, and PTs;

3. to show that the proposed "model," based on knowledge of human nervous system properties using examples of a number of sports and occupations, allows one to predict a wide range of natural psychological characteristics, temperament, and PT that is an alternative to the numerous verbal and nonverbal techniques developed by academic psychology.

\section{Brief history of the case}

Pavlov $^{1}$ undertook a study of the properties of the nervous system (as well as the introduction of the concept itself) to explain differences in the HNA of animals. He then applied the evidence obtained on animals to human habits in behavior and response to the outside environment (ie, temperament types). The identification of the properties of the nervous system by Pavlov was an important step toward the creation of the individual-typical differences theory that served as a basis for the generation of a new scientific discipline: differential psychophysiology, which, in Russia, has been developing for decades. Of no less importance was the development of Pavlov's temperament assessment method that uses a combination of typological features of expression of the properties of the nervous system. Jung's ${ }^{2}$ theory of psychological types emerged approximately at the same time as Pavlov's theory on the properties of the nervous system and the types of HNA. As we know, Jung proposed to distinguish between people on the basis of the degree of expression of each of the four basic mental functions (sensation, intuition, thinking, and feeling) in the context of their extraversion and introversion. Building on Jung's typology, researchers Myers and Briggs ${ }^{3}$ developed a comprehensive questionnaire (Myers-Briggs Type Indicator) to identify 16 different types of character and behavior. Using Jung's theory, researcher Keirsey ${ }^{4}$ developed his own version of the questionnaire to determine the four temperament types and four psychological types within each temperament type. Instead of describing the 16 PTs, Myers and Keirsey identify the types using a combination of English letters, selected from four pairs of opposites: E or I, S or N, T or F, J or P. These letters stand for the following concepts: E - Extroversion, I - Introversion, $\mathrm{S}$ - Sensing, $\mathrm{N}$ - intuition, $\mathrm{T}$ - Thinking, $\mathrm{F}$ - Feeling, $\mathrm{J}$ - Judging, $\mathrm{P}$ - Perceiving.

During the study of the physiological fundamentals of individual differences between people, techniques and appropriate tools for measuring the nervous system properties (NSPs) were developed by the Russian scientific schools of differential psychophysiology. Currently, there are two highly recognized methods that are used in scientific research for measuring the NSPs (strength, mobility, balance) of a person. The first method was developed by Teplov and Nebylitsin ${ }^{5}$ in the 1950s at the Research Institute of General and Educational Psychology of the Russian Academy of Pedagogical Sciences in the differential psychophysiology laboratory, where PNS were determined using data on the electrical activity of the human brain. An alternative method of determining NSP, based on mobility techniques, was suggested in 1972 by Ilyin. ${ }^{6}$ Research in differential psychophysiology testifies that typological characteristics of expression of the properties of the human nervous system are genetically determined and given at birth. ${ }^{7}$ Therefore, they virtually do not change with age or depend on right- or left-handedness or on the characteristics of vision and hearing, which are especially important in the diagnosis of NSP in people with disabilities. Most of the research in differential psychophysiology has identified links between only one or two NSP (most often strength, mobility, or lability of nervous processes) and the psychological characteristics of a person. Ilyin ${ }^{8-11}$ proposed a different approach: a study of various complexes of typological features that affect personality characteristics, behavior, and activity, which can be defined as the study of system-defined impact of NSP on the personality and activity of a person.

\section{Procedure for determination of typological characteristics of NSP}

Differential psychophysiology uses the following definitions of the properties of the nervous system:

The strength of the nervous system is the ability of nerve cells to withstand a powerful stimulus without going into a state of defensive inhibition.

The mobility of excitation and inhibition processes is defined as the rate of disappearance of one process and its replacement by another (high speed corresponds to mobility, 
while low speed corresponds to inertia of the nervous processes).

The equilibrium of nervous processes is the ratio of excitation and inhibition by magnitude.

It should be noted that in the differential psychophysiology, a constructive approach has long been used instead of an "assessment/evaluation approach" (which splits the typological characteristics into "good" and "bad"). This is because the typological characteristics of the NSP determine not so much the degree of human adaptation to the environment as the different forms of balancing the body and environment. ${ }^{12,13}$ The Ilyin's sensorimotor techniques for the assessment of typological characteristics of NSP include tests conducted in the following manner. ${ }^{6}$

In the first test, a method for determining the mobility of excitation and inhibition processes is used. In this case, a graphical version of this technique was applied. Using a special electronic pen compatible with the computer, the testee (with eyes closed) draws straight lines in accordance with the algorithm of commands given by the experimenter. The algorithm of movements proposes a change of tasks to increase or decrease describable lines with regard to a standard selected by the testee. This test reveals how a preceding nervous process, for example excitatory, influences the development of a subsequent inhibitory process, and vice versa. Using a computer, all the movements are recorded and processed, and a measure of mobility of excitation and inhibition is calculated in accordance with predetermined criteria.

In the second test, methods for determining the equilibrium of nervous processes as the ratio of excitation and inhibition according to their magnitude are used. Characteristics of two types of balance are measured: "external" balance, which, by definition, reflects the reaction to the emotionalmotivational aspects of a situation, and "internal" balance, which reflects the energetic aspect of the response. The test for measuring the "external" balance asks the patient (with eyes closed) to draw five segments, with subsequent attempts to accurately reproduce them. The assigned segments are long and short. If the reproduced short and long segments are longer than they should be, then the patient is diagnosed with "dominant excitation." If all segments are shorter, the diagnosis is "predominant inhibition." If the small segments have excess and the long segments are diminished, then it indicates that the nervous processes are in equilibrium. No special procedure for determination of exhibited typological characteristics of the "internal" balance is required. Instead, the data obtained during the test on the mobility of nervous processes are used. In particular, the data are taken from the part of the test where the patient (with eyes closed) performs the following commands: draw a line, then lengthen it a little; take a new line, and shorten it slightly. The task is repeated a number of times on the short and the long segments. A comparison of the total excess and underestimation/ diminishment on the short and the long segments is then performed. If in both short and long segments the total excess is greater than the sum of underestimation, then excitement prevails; if the opposite occurs, then inhibition prevails. In the case when with short segments excess dominates, and with long there is an underestimation, then the nervous processes are said to be in the state of an "internal" balance.

The third test determines the strength of the nervous system, using the tapping test, where temporal changes in the maximum rate of wrist movements of the leading hand are traced with a special device that imitates the operation of the telegraph key and is connected to the computer. In accordance with the instruction, patients do their best to keep the maximum pace for 30 seconds. The pace is recorded every 5 seconds, and using six obtained points, the curve of rate changes of the wrist movements is obtained. The resulting curve types are qualitative criteria of strength intensity of the nervous system. The aim of the tapping test is to obtain the effect of defensive inhibition: patients with a weak nervous system show this effect sooner than those with a strong nervous system. Besides qualitative criteria, quantitative factors of the nervous system strength are determined; they are recorded and then taken into account during their analysis in accordance with the objectives of the study.

Note that the typological characteristics of the NSP in all studies, the results of which are shown below, were measured using a specially designed instrument complex with software and electronic device that we made for implementing Ilyin's motor techniques. ${ }^{14}$

\section{Coding method of typological characteristics of PNS}

For clarity and brevity of the subsequent presentation of research results, it is convenient to introduce and operate with the concept of a "neurodynamic code" that consists of a five-digit number. It symbolically reflects a complex of typological characteristics of the expression of all five NSP of a given patient, with the diagnosis being based on Ilyin's mobile methods. It is conditionally accepted that the first sequential digit in the "code" reflects the strength of the nervous system; the second and third numbers reflect the mobility of excitation and inhibition respectively, while the 
fourth and fifth numbers specify the "external" and "internal" balances of the nervous processes. ${ }^{15}$ Marking the degree of severity of each typology of the five NSP by the digits 1, 2, 3, we obtain the following series:

1. strength of the nervous system: 1 - high, 2 - medium, 3 - weak;

2. excitation processes: 1 - mobile, 2 - partially mobile, 3 - inert;

3. inhibitory processes: 1 - mobile, 2 - partially mobile, 3 - inert;

4. "external" balance: 1 - excitation prevails, 2 - balanced state, 3 - inhibition prevails;

5. "internal" balance: 1 - excitation prevails, 2 - balanced state, 3 - inhibition prevails.

Different variants of neurodynamic codes can be written as $31133,23311,12231,23313,31221,11133,33313$, etc. For example, code 11133 can be decoded as follows: a strong nervous system (1), mobility of excitation (1) and inhibition (1), on the "external" and "internal" balances, inhibition prevails (a combination of balances - 33). Code 33313 can be read as: weak nervous system (3), inertia of the excitation (3) and inhibition (3), on the "external" balance excitation dominates (1), on the "internal" balance inhibition prevails (3). Mathematically, the total number of possible combinations of the NSP, ie, the number of neurodynamic codes in the three-tier system of evaluation of the degree of each of the five properties, is 243. Obviously, in practice, it is difficult to operate with such a large number of NSP combinations. Thus, they must be grouped by selecting a relatively small number of base combinations, which will be applied below when the experimental results are generalized.

\section{Results of the study of typological characteristics of the properties of the nervous system in the professions and sports}

To determine the typological characteristics of NSP that promote functioning efficiency, we conducted studies on a number of professions ${ }^{16,17}$ and sports. ${ }^{18-21}$ Data on the frequency of occurrence of major combinations $(11,31,33,13)$ of the "external" and "internal" balances of the nervous processes in the professions and sports are shown in Table 1.

In our study, Paralympic athletes, as well as representatives of pair skating, are very skilled at sports and are part of the national teams of Russia, and many of them are participants in international competitions, winners of the World Cup series, World Championships, and the Paralympic Games. Other athletes are representatives of sports schools and the Figure Skating Academy (single); they are members of the teams of St Petersburg in their respective sports.

Complete data on the frequency of occurrence of the properties "power" and "mobility" of the neural processes in these sports and occupations are not listed here. We merely note that a strong nervous system is more common in the following groups: sailing ( $56.5 \%$ in the sample); powerlifting (64.3\%); skiing, biathlon (65.5\%); sledge hockey defensemen (69.2\%); Special Forces soldiers (81.0\%); caregivers in orphanages (67.6\%); dentists (62.5\%); dental nurses (66.5\%). Dominance of the high mobility of excitation and inhibition occurred among representatives of the following groups: figure skating (all disciplines), archery, basketball, sailing, sledge hockey forward, sprint $(100,200 \mathrm{~m})$, throws (short put, discus, javelin). In the other groups under study, a mild nervous system and inertness of the nervous processes occurred.

Note that the statistical method of angular transformation $(F$-test) was used to detect the observed differences in the frequency of occurrence of the four basic combinations of "external" and "internal" balance of nervous processes in the experimental groups, as shown in Table 1. These groups consisted of athletes and representatives of a number of professions, which were students of schools and gymnasiums, chosen for comparison with the results of a previous study ${ }^{15}$ (sample size $-1,513$ students, $6-18$ years of age). On the basis of these data, we can identify statistically significant patterns:

1. The predominance of excitation by "external" and "internal" balances (combination option - 11) is often observed in groups: figure skating (single), cross-country skiing, biathlon, sprinting, throws (short put, discus, javelin), powerlifting, sledge hockey defensemen, Special Forces soldiers, teachers and psychologists (education). However, it occurs rarely in the groups archery and taekwondo.

2. The predominance of inhibition by the "external" balance and of excitation by the "internal" balance (combination 31) is often found in the groups figure skating (ice dancing, single), basketball, and taekwondo. It is uncommon in the groups archery, shooting, powerlifting, sledge hockey defensemen, Special Forces soldiers, and dental nurses.

3. The predominance of inhibition by the "external" and "internal" balance (combination 33) is often found in the groups archery, dentists. However, it is rare in the groups figure skating (single), skiing, sprint, ski jumping, the sledge hockey defensemen, sailing, teachers, psychologists, and Special Forces soldiers. 
Table I The determining typological characteristics of NSP in the sporting professions

\begin{tabular}{|c|c|c|c|c|c|c|}
\hline \multirow[t]{2}{*}{ Number } & \multirow[t]{2}{*}{ Sport/professional occupation } & \multirow[t]{2}{*}{$\begin{array}{l}\text { Sample size } \\
\text { (n) }\end{array}$} & \multicolumn{4}{|c|}{$\begin{array}{l}\text { Frequency of occurrence of major } \\
\text { combinations }(I I, 3 I, 33, I 3) \text { of the "external" } \\
\text { and "internal" balances of the nervous } \\
\text { processes in the professions and sports }(\%)\end{array}$} \\
\hline & & & II & 31 & 33 & 13 \\
\hline $\mathrm{I}$ & Figure skating, dancing & 28 & 25.0 & $46.4^{* * * *}$ & 21.4 & $7.2^{* * *}$ \\
\hline 2 & Figure skating, singles & 31 & $45.2^{*}$ & $38.7^{* *}$ & $9.7^{* *}$ & $6.4^{* *}$ \\
\hline 3 & Figure skating, pairs & 17 & 35.3 & 23.5 & 35.3 & $5.9 *$ \\
\hline 4 & Artistic gymnastics & 29 & 34.5 & 13.8 & 20.7 & 31.0 \\
\hline 5 & Shooting & 11 & 27.3 & 9.0 & 18.2 & 45.5 \\
\hline 6 & Archery & 14 & $7.1^{*}$ & $0.0 * * *$ & $50.0 *$ & 42.9 \\
\hline 7 & Basketball & 13 & 30.8 & $53.8 * *$ & 15.4 & $0.0 * * *$ \\
\hline 8 & Taekwondo & 23 & 17.4 & $39.1 *$ & 39.1 & $4.4^{* *}$ \\
\hline 9 & Cross-country skiing & 15 & $66.7 * * *$ & 13.3 & $0.0^{* * * *}$ & 20.0 \\
\hline 10 & Ski jumping & 15 & 26.7 & 20.0 & 13.0 & 40.0 \\
\hline 11 & Sailing & 92 & 33.7 & 15.7 & $15.7^{* *}$ & $34.9 *$ \\
\hline \multicolumn{7}{|c|}{ Paralympic sports } \\
\hline 12 & Sprints $(100,200 \mathrm{~m})$ & 17 & $52.9 *$ & 23.5 & $11.8^{*}$ & 11.8 \\
\hline 13 & Throws (Shot put, discus, javelin) & 14 & $50.0 *$ & 14.3 & 21.4 & 14.3 \\
\hline 14 & Powerlifting & 28 & $53.6 * *$ & $7.1^{*}$ & 17.9 & 21.4 \\
\hline 15 & Middle-distance $(800,1,500 \mathrm{~m})$ & 13 & 30.8 & 15.3 & 23.1 & 30.8 \\
\hline 16 & Cross-country skiing, Biathlon & 29 & 41.4 & 20.7 & $6.9 * * *$ & 31.0 \\
\hline 17 & Alpine skiing & 18 & 22.2 & 16.7 & 16.7 & $44.4^{*}$ \\
\hline 18 & Sledge hockey, forward & 15 & 33.3 & 13.3 & 33.3 & 20.1 \\
\hline 19 & Sledge hockey, defensemen & 13 & $53.8^{*}$ & 7.7 & $7.7^{*}$ & 30.8 \\
\hline \multicolumn{7}{|c|}{ Professional occupancy } \\
\hline 20 & Special Forces soldiers & 21 & $76.2^{* * *}$ & $4.8^{*}$ & $0.0 * * *$ & 25.0 \\
\hline 21 & School teachers & 65 & $55.4^{* * *}$ & 26.2 & $6.1^{* * * *}$ & $12.3^{*}$ \\
\hline 22 & Psychologists in education & 33 & 42.4 & 15.1 & $15.1^{*}$ & 27.4 \\
\hline 23 & Caregivers in orphanage & 37 & 29.7 & 16.2 & 16.2 & $37.9 *$ \\
\hline 24 & Dentists & 24 & 33.6 & 16.4 & $46.2^{*}$ & $4.2 * *$ \\
\hline 25 & Dental nurses & 29 & 31.0 & 10.3 & 34.5 & 24.1 \\
\hline
\end{tabular}

Notes: Combination option II is the predominance of excitation by "external" and "internal" balances. Combination option $3 \mathrm{I}$ is the predominance of inhibition by the "external" balance and of excitation by the "internal" balance. Combination option 33 is the predominance of inhibition by the "external" and "internal" balance. Combination option I 3 is the predominance of excitation by "external" balance and of inhibition by "internal" balance. Marked significance level of $* P<0.05$, $* * P<0.0 \mathrm{I}$, $* * * P<0.00 \mathrm{I}$; and figures in bold $P>0.1$ (F-test). In Paralympic sports, athletes with lesions of the musculoskeletal system are presented, while the sports in bold (numbers I2, I3, I5, I7) are those where in addition to athletes with lesions of the musculoskeletal system, there are only visually impaired athletes.

Abbreviation: NSP, nervous system properties.

4. The predominance of excitation by "external" balance and of inhibition by "internal" balance (combination 13) is often observed in the groups shooting, archery, ski jumping, skiing, sailing, and orphanage caregivers. It is uncommon in the groups figure skating (all disciplines), basketball, taekwondo, teachers, and dentists.

Data on the frequency of occurrence of the main combinations of properties "external" and "internal" balances of the nervous processes among the athletes in sports considered here allow us to propose the following assumptions:

1. a combination of balances 31 combines sports where an important part is the need to make multiple jumps vertically upward, overcoming the force of gravity vector (figure skating, basketball, taekwondo);

2. a combination of balances 13 combines sports where an important part is the need for monitoring and control of the movements under the effect of a variety of natural forces, including the downward movement under the force of gravity (sailing, shooting, archery, ski jumping, alpine skiing);

3. a combination of balances 11 combines sports where an important element is the need to make impulsive movements along or at relatively small angles to the horizontal surface (cross-country skiing, biathlon, sprint, long-distance race, throws, hockey);

4. a combination of balances 33 , compared with combinations $11,31,13$, is significantly less common in sports that are presented in this study.

These assumptions require some additional research.

The data in Table 1 also indicate that among sport and dance pairs in figure skating, as well as doctors and nurses (in dentistry), with relatively equal frequency, are found contrary combinations 11 and 33 of the properties "external" and "internal" balance of nervous processes. 
Perhaps in these sports and in stomatology (dentists and nurses work using "four" hands), formation of a functional pair of athletes or experts with contrary but complementary TCs of the NSP is the most preferred. This tendency may indicate the need to take into account psychophysiological and, accordingly, psychological compatibility in sports and professions (athlete to athlete, coach to athlete, and expert to expert). Our studies show that in individual sports, such as skiing and biathlon, typological characteristics of NSP of a coach and an athlete closely correspond, and it is probably an important and necessary condition for the effective transfer of knowledge and skills from the teacher to the student. ${ }^{22}$

\section{The connection between typological characteristics of NSP and the properties of temperament}

In order to study the connections between the properties of the nervous system and the properties of temperament, we conducted a study where the experimental group was formed by students from different departments of the Russian State Pedagogical Gertsen University in St Petersburg. ${ }^{23,24}$ The sample of students was 453 people, comprising 369 girls and 84 boys, the average age being 22.2 years. For the diagnosis of NSP, we used Ilyin's mobility methodologies, and to determine the properties of temperament, the questionnaires of Keirsey and Aizenk (EPQ, Form A). The study revealed TCs of PNS caused by the degree of expression of the following mental functions:

Sensation (S): weak nervous system, high mobility of excitation, low motility of inhibition, domination of excitation in the "external" and "internal" balances (31311).

Intuition $(\mathrm{N})$ : strong nervous system, low mobility of excitation, high mobility of inhibition; predominance of inhibition in the "external" and "internal" balances (13133).

Thinking (T): strong nervous system, low mobility of excitation, high mobility of inhibition, predominance of inhibition in the "external" balance, equilibrium in the "internal" balance (probable code - 13132, which suggests combinations 13131 and 13133).

Feeling (F): weak nervous system, high mobility of excitation, low mobility of inhibition, equilibrium in the "external" balance, predominance of inhibition in the "internal" balance (probable code of TC -31323 , which suggests possible combinations 31313 and 31333).

The study also identified TCs of PNS that cause high or low degree of the following properties of temperament (by Ayzenk):
Low neuroticism: strong nervous system, low mobility of excitation and inhibition, predominance of inhibition in the "external" balance, predominance of excitation in the "internal" balance (complex code - 13331).

High neuroticism: weak nervous system, high mobility of excitation and inhibition, equilibrium or inhibition in the "external" balance, predominance of inhibition in the "internal" balance (complex code - 31123, which in addition suggests a combination of 31113 or 31133 ).

Extraversion (E): weak nervous system, low mobility of excitation, high mobility of inhibition, predominance of inhibition in the "external" and "internal" balances (code - 33133).

Introversion (I): strong nervous system, high mobility of excitation, low motility of inhibition, predominance of excitation in the "external" and "internal" balances (code - 11311).

Note that TCs of NSP causing the intensity of properties "extroversion" and "introversion" were defined in this study in accordance with two questionnaires written by Keirsey and Aizenk, and they coincided by composition.

It is important to bear in mind that the experimental studies carried out by representatives of differential psychophysiology in Russia ${ }^{8-11,25}$ revealed a large number of TCs of NSP causing high or low intensity of psychological phenomena, the list of which is given in Table 2 .

The psychological phenomena presented in Table 2 should be considered in the context of the concepts of conditional positive and negative TCs. Positive TC is such a combination of typological characteristics of NSP when all the properties unidirectionally make for a high degree of phenomenon expression; negative TC takes place when all the properties unidirectionally prevent the manifestation of the phenomenon, resulting in its low expression. It is essential that the TC compositions causing a high degree of expression of one or another psychological phenomenon should be determined experimentally for a large number of patients, and the NSP of a person should be measured by instrumental methods, as opposed to attempting to assess their expression on the basis of all sorts of questionnaires. Furthermore, it is impossible to conclude that a person has one or another typological feature of expression of NSP, relying on behavioral characteristics and activity efficiency, where the latter can be achieved through knowledge and skills, on the one hand, and due to the different predispositions, including the different typological characteristics, on the other.

In one of our experimental studies, we have demonstrated that knowledge of composition of TCs, causing the intensity of psychological phenomena, and knowledge of typological characteristics of NSP of a person make it possible to reliably 
Table 2 Psychological phenomena for which, in differential psychology, the composition of the typological complexes of NSP causing high or low degree of their expression is known

\begin{tabular}{|c|c|c|c|}
\hline $\begin{array}{l}\text { Characteristics of } \\
\text { psychomotor system }\end{array}$ & $\begin{array}{l}\text { Characteristics of } \\
\text { individual style of activity }\end{array}$ & $\begin{array}{l}\text { Characteristics of } \\
\text { intellectual tension }\end{array}$ & $\begin{array}{l}\text { Resistance to adverse conditions, } \\
\text { volitional features }\end{array}$ \\
\hline Motor memory & $\begin{array}{l}\text { Duration of preparation } \\
\text { for activity }\end{array}$ & $\begin{array}{l}\text { Promptitude of formation } \\
\text { of the visual image }\end{array}$ & Emotional and mental stability \\
\hline Sense of balance, coordination & Pace of activity start-up & Undefined memory & Courage in stressful situations, determination \\
\hline Complex response rate & Pace of learning & Unintentional memory & Working until a sign of fatigue \\
\hline $\begin{array}{l}\text { Speed of simple motor } \\
\text { response }\end{array}$ & $\begin{array}{l}\text { Planning, spontaneity } \\
\text { of action }\end{array}$ & Concentration of attention & Critical thinking, creativity \\
\hline Sprint inclinations & $\begin{array}{l}\text { Adaptability to dynamic } \\
\text { situations }\end{array}$ & Ability to switch attention & Adaptability to adverse environmental factors \\
\hline Stayer inclinations & $\begin{array}{l}\text { Propensity to competition, } \\
\text { leadership }\end{array}$ & Speed of thought process & $\begin{array}{l}\text { Patience, perseverance, working when } \\
\text { fatigued }\end{array}$ \\
\hline Recovery process rate & & Mindset: artistic, intellective & Resistance to monotonic condition \\
\hline
\end{tabular}

Abbreviation: NSP, nervous system properties.

predict high or low expression of these phenomena for this person. ${ }^{24}$ Obviously, this conclusion applies to psychological phenomena studied in our research as well as in the works of the other researchers. ${ }^{8-11,25} \mathrm{~A}$ list of psychological phenomena for which the composition of TCs causing them is known is presented in Table 2. This knowledge represents the practical significance of scientific achievements of differential psychophysiology.

\section{Spatial model of the connection between TCs of the properties of the nervous system, temperaments, and PTs}

Above, when considering the results of experimental studies in education, professions, and sports, as a basis, we adopted the four possible combinations of two properties: the "external" and "internal" balances of the nervous processes (combination - 11, 33, 13, 31). Further, considering two levels of expression of the "strength" of the nervous system (strong or weak) and two levels of the expression of the "mobility" of excitation and inhibition (high or low), all possible combinations of NSP can be grouped into 16 core combinations of NSP (TCs). If we consider three levels of expression of the strength of the nervous system (strong, medium, weak), we would have 24 complexes, and when we go from two to three grades of the mobility of excitation and inhibition (high, medium, low) we can get 36 TCs. Taking into consideration the principal aim of our work, we will focus on the 16 TCs of NSP. We should recall that when developing his teachings about the types of HNA, the physiologist Ivan Pavlov suggested only four variants of NSP combinations - four types of HNA, which scientists have correlated with the known types of temperaments: choleric, sanguine, phlegmatic, and melancholic.

To establish the adequacy of the variety of TCs that we grouped into 16 principal combinations of the properties of the nervous system to psychological types considered in the teaching of Carl Jung (8 types), as well as in the works of Myers and Keirsey (16 types), we needed to find a unifying coordinate system for "complexes" and "types." For this purpose, the scheme of cardinal points N, S, E, $\mathrm{W}$ worked well. In this scheme, it is easy to reflect the four basic combinations of two properties: the "external" and "internal" balances of the nervous processes (combination $11,31,33,13$ ) and four mental functions allocated by Jung - sensation, intuition, thinking, and feeling. The initial challenge was to orient the "balances" and the "functions" in the spatial scheme of the coordinate points, as well as to find a place in this scheme for the properties "extroversion" and "introversion." To do this, we have proposed the principle of "rings" superimposed on the spatial pattern N, S, E, W, where the outer ring is assigned to the property "introversion" and the inner ring to the property "extraversion." The principle of "ring" allowed us to determine "extroversion" and "introversion" of each of the four mental functions, "tied" to the scheme N, S, E, W, so that the functions of the "sensation" correspond to the North, "intuition" to the South, "thinking" to the East, and "feeling" to the West. This is reflected in the spatial "model" in Figure 1, which concurrently shows the "binding" of the typological characteristics of PNS to the scheme N, S, E, W.

Such a "binding" was justified by the following fact. As has been shown above, the mental function "sensation" is due to a TC, which along with a strong nervous system and the high mobility of excitation and inhibition also includes the 


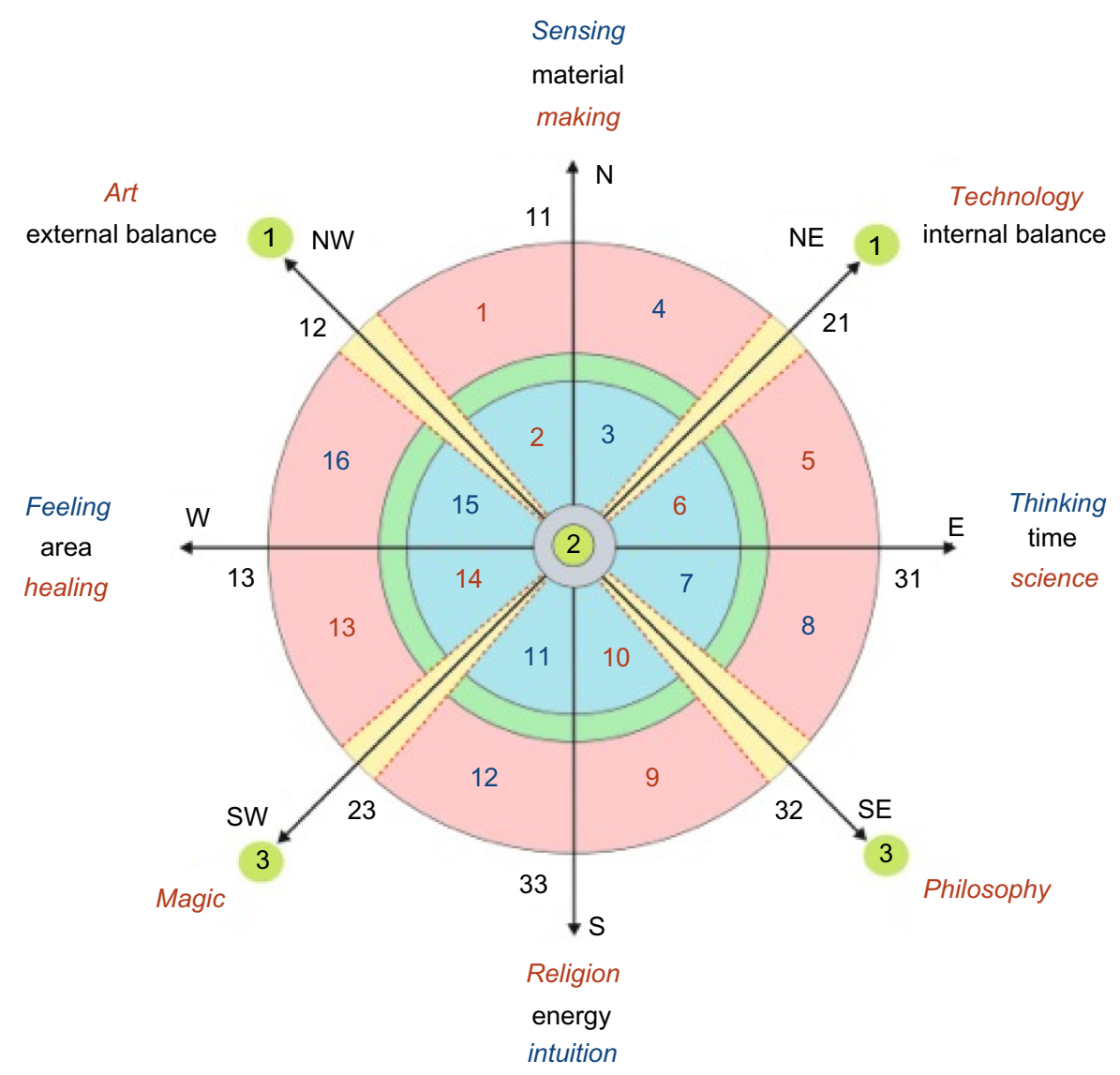

Figure I Spatial model of the communication between the typological complexes of the properties of the nervous system, temperaments, and psychological types.

Notes: The principle of the "ring" determines "extroversion" and "introversion" in each of the four mental functions, "tied" to the scheme N, S, E, W, so that the functions of the "sensation" correspond to the North, "intuition" to the South, "thinking" to the East, and "feeling" to the West. The figures that are highlighted in green represent the change of the "internal" balance from excitation (I) through the balance (2) to the predominance of inhibition (3) are reflected. The figures within the model, I-I6, relate to the zone numbers (Table 3).

Abbreviations: N, north; E; east; S, south; W, west; NE, northeast; NW, northwest; SE, southeast, SW, southwest.

predominance of excitation in the "external" and "internal" balances (combination of balances - 11). Accordingly, mental function "intuition" is due to the opposite set of properties, which include the predominance of inhibition in both balances (combination 33). Mental function "thinking" is due to the TC, which includes the predominance of inhibition in the "external" and the predominance of excitation in the "inner" balances (combination 31). Accordingly, mental function "feeling" is caused by the opposite composition of TC, which includes the predominance of excitation in the "external" and inhibition in the "internal" balances (combination 13). In the choice of "binding" of TCs and psychological types in the spatial pattern N, S, E, W, it was important to take into account a known scientific fact, namely, that the two properties - the "external" and "internal" balances of the nervous processes - are independent of each other in terms of levels of regulation of the brain activities (respectively, emotionalmotivational level and a level that reflects vitality, energy, and the need for activity). ${ }^{10,13,24}$ Therefore, the "balances" are orthogonal in the defined coordinate system, and it is shown in the "model" in Figure 1 by two perpendicular lines. In the direction from NW to SE, the change of the "external" balance from excitation (number 1), through the balance (2) to the predominance of inhibition (3) is shown. Similarly, in the direction from NE to SW, the change of the "internal" balance from excitation (number 1) through the balance (2) to the predominance of inhibition (3) is reflected. Thus, in the spatial "model" in Figure 1, for the choice of combination 11 of the properties "external" and "internal" balances, there is a sector in the northerly direction where mental function "feeling" is also placed. Combination 31 of the balances and the function "thinking" are placed in the eastern sector, the combination 33 and the function "intuition" in the southern sector, and the combination 13 and the function "feeling" in the Western sector.

We also applied the principle of the "ring" to the property "strength" of the nervous system. Therefore, the properties "introversion" and "strong nervous system" are combined in 
the outer ring in the "model." The properties "extraversion" and "weak nervous system" are combined in the inner ring. Such a combination is justified by the fact that the TC of NSP that causes a high expression of the "introversion" includes a "strong nervous system," while a complex that causes a high expression of the "extroversion" includes a "weak nervous system."

In the book Please Understand Me - II, Keirsey ${ }^{4}$ notes that Carl Jung and Myers exaggerate the role of the properties "extroversion" and "introversion" in the manifestation of psychological types. From our point of view, it is not true. It is known that the property "extraversion" characterizes sociability, socialization, interaction, breadth of views and interests, the radiation of energy, and interest in external events; while "introversion" characterizes insularity, a sense of personal territory, introspection, isolation, depth, thoroughness, energy conservation, and an interest concerning internal reactions. Taking into account the traditional approach, it is still necessary to add the concept "stress-resistance" to the understanding of these properties of temperament, for two reasons. First, as shown by studies in differential psychophysiology, individuals with a strong nervous system are more stress-resistant. For example, in Table 2, the high expression of psychological phenomena, included in the category "resistance to adverse conditions, volitional features," to a great degree depends on the typological characteristic "strong nervous system," while the "weak nervous system" in this category of phenomena causes only resistance to monotony. Second, in one of our studies, we have shown that a strong nervous system in the appropriate TC leads to a high expression of the property "introversion" and a weak nervous system leads to a high expression of "extraversion." 24 These facts point to the applicability of evaluating "high stress" to the property "introversion," and "low stress" to the property "extraversion." Note that a weak nervous system has not only a negative side (nonresistance to stress), but also a positive side, which includes high sensitivity. 5,12,13

Apart from the four sectors of the key areas N, S, E, W in the spatial "model" in Figure 1, we designated four smaller sectors zones of conditionally "minor" combinations of the "external" and "internal" balances: combination 12 - in the direction NW, combination 21 - NE, combination $32-\mathrm{SE}$, and combination $23-\mathrm{SW}$. As already noted, the patients with combinations where in one of the balances the typological characteristic "balance" appears can be referred to the appropriate key sector. For example, in the case of the combination of the balances 12 (NW sector), the patient is defined either in the northern sector (a combination of balances 11) or in the Western (a combination of balances 13), respectively, depending on whether there is a shift in the "internal" balance toward excitation (1) or inhibition (3). This patient can be conditionally called "courier," which would indicate the possibility of his "transition" from one sector to another and so from one PT to another, and vice versa. As our research revealed, among the students of schools and gymnasiums, the percentage of patients with the typological characteristic "equilibrium" in the "external" and (or) the "internal" balances of the nervous processes was $22 \%$, which points to the possible number of "couriers" in the total sample. ${ }^{15}$

The TCs may include five NSPs, three of which - the "strength of the nervous system" as well as "external" and "internal" balances - are already reflected in the "model" in Figure 1. Thus, the next stage of its formation was the necessity to clarify in the scheme N, S, E, W the position of two more properties of the nervous system - the "mobility" of excitation and inhibition. In the "model" in Figure 1, each of the four major sectors is divided into two portions by a vertical line, N-S, and a horizontal line, W-E. We proposed to arrange the combinations of properties "high" mobility of excitation and inhibition (combination of the second and third digits in neurodynamic code -11) in one portion of any sector, and a combination of properties "low" mobility of excitation and inhibition (combination code - 33) in another

Table 3 The connection between the TCs of PNS, temperaments, and PTs, reflected in the spatial "model"

\begin{tabular}{|c|c|c|c|c|}
\hline $\begin{array}{l}\text { Zone } \\
\text { number in } \\
\text { the "model" }\end{array}$ & $\begin{array}{l}\text { Digital } \\
\text { code TC } \\
\text { of PNS }\end{array}$ & $\begin{array}{l}\text { Letter } \\
\text { code } \\
\text { PT }\end{array}$ & $\begin{array}{l}\text { PT name } \\
\text { (by Keirsey) }\end{array}$ & $\begin{array}{l}\text { Temperament } \\
\text { name } \\
\text { (by Keirsey) }\end{array}$ \\
\hline I & 11111 & ISFP & Composer & Artisan \\
\hline 2 & 31111 & ESFP & Performer & Artisan \\
\hline 3 & 33311 & ESTJ & Supervisor & Guardian \\
\hline 4 & $|33| \mid$ & IST] & Inspector & Guardian \\
\hline 5 & 11131 & ISTP & Crafter & Artisan \\
\hline 6 & 31131 & ESTP & Promoter & Artisan \\
\hline 7 & 33331 & ENTJ & Field marshal & Rational \\
\hline 8 & $|333|$ & INTJ & Mastermind & Rational \\
\hline 9 & 11133 & INTP & Architect & Idealist \\
\hline 10 & 31133 & ENTP & Inventor & Idealist \\
\hline II & 33333 & ENFJ & Teacher & Rational \\
\hline 12 & 13333 & INFJ & Counselor & Rational \\
\hline 13 & 11113 & INFP & Healer & Idealist \\
\hline 14 & 31113 & ENFP & Champion & Idealist \\
\hline 15 & 33313 & ESFJ & Provider & Guardian \\
\hline 16 & 13313 & ISFJ & Protector & Guardian \\
\hline
\end{tabular}

Notes: In the five-digit code of the typological complex of NSP, the sequence of the properties is as follows: 1 ) the strength of the nervous system (I - strong, weak - 3 ); 2 ) the mobility of excitation; 3 ) the mobility of inhibition (I - high mobility, 3 - low mobility); 4) "external" balance; 5) "internal” balance (I - excitation prevails, 3 inhibition prevails). The "model" relates to Figure I.

Abbreviations: TCs, typological complexes; PNS, properties of the nervous system; PTs, personality types; E, Extroversion; I, Introversion; S, Sensing; N, intuition; T, Thinking; F, Feeling; J, Judging; P, Perceiving. 
portion of the same sector. The areas with high mobility of excitation and inhibition in the "model" in Figure 1 are marked with numbers 1 and 2, 5 and 6,9 and 10,13 and 14 . Areas with low mobility of neural processes are marked with numbers 3 and 4, 7 and 8,11 and 12,15 and 16. The portion of the sector with high mobility of the nervous processes reflect the temperament property $\mathrm{P}-$ Perceiving. The portion of the sector with low mobility of the nervous processes reflects the property $\mathrm{J}-$ Judging. Such an arrangement is based on the fact that in the "Myers-Briggs Type Indicator" under the concepts of $\mathrm{P}$ - Perceiving and $\mathrm{J}$ - Judging introduced by Carl Jung, his successor, I. Myers, implies JScheduling and P - Probing, respectively. Keirsey shares this position. On the other hand, studies have shown that the "inertia" of the nervous processes determines the propensity of an individual to plan his actions, and "mobility" of the

Table 4 Prognosis of PTs and temperaments made on the basis of the spatial "model" and composition of typological complexes of NSP dominating in sports and professions

\begin{tabular}{|c|c|c|c|c|}
\hline Sports, profession & $\begin{array}{l}\text { Zone number } \\
\text { in the "model" }\end{array}$ & $\begin{array}{l}\text { Digital code } \\
\text { TC of PNS }\end{array}$ & $\begin{array}{l}\text { Letter } \\
\text { code PT }\end{array}$ & $\begin{array}{l}\text { Temperament } \\
\text { name (by Keirsey) }\end{array}$ \\
\hline \multirow[t]{3}{*}{ Figure skating (dance, pairs) } & 2 & 31111 & ESFP & Artisan \\
\hline & 6 & 31131 & ESTP & Artisan \\
\hline & 10 & 31133 & ENTP & Idealist \\
\hline \multirow[t]{2}{*}{ Figure skating (singles), Basketball } & 2 & 31111 & ESFP & Artisan \\
\hline & 6 & 3|| $3 \mid$ & ESTP & \\
\hline Artistic gymnastics, shooting, & 3 & 33311 & ESTJ & Guardian \\
\hline long-distance running & 15 & 33313 & ESFJ & \\
\hline \multirow[t]{2}{*}{ Archery } & 9 & 11133 & INTP & Idealist \\
\hline & 10 & 31133 & ENTP & \\
\hline \multirow[t]{2}{*}{ Taekwondo } & 6 & $3113 \mid$ & ESTP & Artisan \\
\hline & 10 & 31133 & ENTP & Idealist \\
\hline \multirow[t]{2}{*}{ Cross-country skiing } & 3 & 33311 & ESTJ & Guardian \\
\hline & 4 & $1331 \mid$ & ISTJ & \\
\hline \multirow[t]{2}{*}{ Ski jumping } & 13 & 11113 & INFP & Idealist \\
\hline & 14 & 31113 & ENFP & \\
\hline \multirow[t]{3}{*}{ Sailing } & 1 & 11111 & ISFP & Artisan \\
\hline & 13 & 11113 & INFP & Idealist \\
\hline & 16 & 13313 & ISFJ & Guardian \\
\hline \multicolumn{5}{|l|}{ Paralympic sports } \\
\hline Sprint, throws (shot put, discus, javelin) & 2 & 31111 & ESFP & Artisan \\
\hline \multirow[t]{2}{*}{ Powerlifting } & 1 & 11111 & ISFP & Artisan \\
\hline & 4 & 13311 & ISTJ & Guardian \\
\hline \multirow[t]{3}{*}{ Cross-country skiing, biathlon } & 3 & 33311 & ESTJ & Guardian \\
\hline & 4 & $133 \mid 1$ & IST] & \\
\hline & 16 & 13313 & ISFJ & \\
\hline \multirow[t]{2}{*}{ Alpine skiing } & 13 & 11113 & INFP & Idealist \\
\hline & 14 & 31113 & ENFP & \\
\hline \multirow{2}{*}{ Sledge hockey, forward } & 2 & 31111 & ESFP & Artisan \\
\hline & 10 & 31133 & ENTP & Idealist \\
\hline \multirow[t]{2}{*}{ Sledge hockey, defensemen } & 4 & $133 \mid 1$ & IST] & Guardian \\
\hline & 16 & 13313 & ISFJ & \\
\hline \multicolumn{5}{|l|}{ Professional occupations } \\
\hline Special Forces soldiers, & 4 & 13311 & IST] & Guardian \\
\hline Caregivers in orphanage & 16 & 13313 & ISFJ & \\
\hline \multirow[t]{2}{*}{ School teachers } & 3 & 33311 & ESTJ & Guardian \\
\hline & 7 & 33331 & ENTJ & Rational \\
\hline \multirow[t]{2}{*}{ Psychologists in education } & 3 & 33311 & ESTJ & Guardian \\
\hline & 15 & 33313 & ESFJ & \\
\hline \multirow[t]{2}{*}{ Dentists, dental nurses } & 4 & $133 \mid 1$ & IST] & Guardian \\
\hline & 12 & 13333 & INFJ & Rational \\
\hline
\end{tabular}

Notes: Sports or professions combined into one group are characterized by the same personality types and temperaments. In the five-digit code of the typological complex of NSP, the sequence of the properties is as follows: I) the strength of the nervous system (I - strong, weak - 3); 2 ) the mobility of excitation; 3 ) the mobility of inhibition (I - high mobility, 3 - low mobility); 4) "external” balance; 5) "internal” balance (I - excitation prevails, 3 - inhibition prevails). The "model” relates to Figure I.

Abbreviations: PTs, personality types; PNS, properties of the nervous system; NSP, nervous system properties; TC, typological complex; E, Extroversion; I, Introversion; S, Sensing; N, intuition; T, Thinking; F, Feeling; J, Judging; P, Perceiving. 
nervous processes affects the propensity to spontaneous action. $^{26}$

Taking into account all of the above facts, the spatial model of the connection of the TCs of the properties of the nervous system, temperaments, and PTs takes the form shown in Figure 1. For a better perception and understanding of the "model," one can also refer to Table 3, where numeration of 16 zones reflects in the scheme of N, S, E, W. Each of these zones accommodates the TCs of NSP that determine a high degree of expression of the sixteen corresponding PTs, four types for each of the four temperaments (by Keirsey). Note that in the spatial "model," the TCs of NSP correspond to Keirsey's PTs. The "model" has a slightly different form if it includes 16 psychological types by Myers. The reason lies in the differences in the views of these researchers on the role of mental functions for the formation of PTs. The nature of the connection between the complexes and types in the "model" will remain unchanged, as reflected in Table 3.

\section{Prediction of PTs and temperaments in the professions and sports}

On the basis of the spatial "model," which sets the natural connections between TCs of the properties of the nervous system, temperaments, and PTs reflected in Figure 1 and Table 3, and the data on the frequency of occurrence of typological characteristics of properties "strength" of the nervous system, "mobility" of excitation and inhibition, "external" and "internal" balances of the nervous processes (Table 1), all together allow us to predict temperaments and PTs that dominate the studied sports and professions. The results of the prognosis are presented in Table 4.

On the basis of the prognosis presented in Table 4, we can assume that in the sports studies, people with the following temperaments dominate (by Keirsey): "artisan," "guardian," and "idealist." The temperament "rational" in these sports is not represented, although in the studied professions such a presence is noticeable.

It should be emphasized that any prognosis implemented on the basis of experimentally identified TCs of NSP is associated with the identification of the natural inclinations for a successful carrier rather than with the prediction of a particular result. In the very possibility of predicting the efficiency of an individual's activity in accordance with his typological characteristics lies the main meaning of its study in differential psychophysiology. It opens a prospect of predicting with a certain probability how a person will behave in a given situation, which abilities he manifests to a higher degree and, to a lesser degree, what activity style is more suitable for him/her, etc. However, as it was already noted, for a successful application of this approach, not just one typological characteristic should be used (as has been done in the majority of known studies), but a complex of typological characteristics, which may cause the expression of a given psychological phenomenon.

For practical implementation of the motor techniques by Ilyin, we developed a hardware-software complex, "Prognosis," that allows one to conduct fast (no more than 10-15 minutes) identification of the full composition of the TC of NSP of a person (over 6 years old), to carry out prognosis of his/her psychological characteristics - psychomotor, personal style of activity, intellectual activity, resistance to adverse conditions and volitional characteristics, temperament, and PT. ${ }^{14,27}$ At the same time, for characterization of the person, there are opportunities to use rich empirical material obtained in the course of many years of research in differential psychophysiology in Russia, as well as that presented in the works of Myers and Keirsey, and other followers of Jung's theory of psychological types.

\section{Conclusion}

Importantly, the proposed "model" of the connections between the TCs of the NSP, temperaments, and PTs was formed on the basis of experimental studies aimed at the justification of the possibility to predict a person's natural characteristics, temperament, and PT in a wide age range, on the basis of knowledge of the typological characteristics of expression of the properties of the nervous system of the person, without using questionnaires. This allows one to understand himself as early as possible, to detect his/her inclinations and capabilities, to build personal relationships, and for professionals - to help people in social adaptation and in choosing a suitable profession, in solving health problems and, in practice, an individual approach to everyone who asks for help.

\section{Disclosure}

The author reports no conflicts of interest in this work.

\section{References}

1. Pavlov IP. Twenty Years of Objective Study of the Higher Nervous Activity of Animals. Leningrad, Russia: Medgiz; 1951.

2. Jung CG. Psychological Types. St Petersburg, Russia: Uventa; 1995.

3. Myers I, Myers P. MBTI: Type Indicator. Every Person has His Own Talent. Moscow, Russia: Business Psychology; 2012.

4. Keirsey D. Please Understand Me - II. Temperament. Character. Intellect Moscow, Russia: Chernaya Belka; 2011.

5. Teplov BM, Nebylitsin VD. Study of the main properties of the nervous system and their importance for the psychology of the individual differences. Problems Psychol. 1963:5. 
6. Ilyin EP. Strength of the nervous system and the methods of its study (p. 5-15); Express-method of determination of the degree of expression of the properties "mobility-inertia" of excitation and inhibition (p. 16-36); Property of balance by degree of excitation and inhibition and methods of its study (p. 37-57). Psychological Grounds of Physical Education and Sports. Leningrad, Russia; Science. 1972.

7. Ravich-Shcherbo IV. The Role of Environment and Heredity in Shaping Human Individuality. Moscow, Russia: Pedagogica; 1988.

8. Ilyin EP. Differential Psychology. St Petersburg, Russia: Peter; 2001.

9. Ilyin EP. Differential Psychology in Professions. St Petersburg, Russia: Peter; 2008.

10. Ilyin EP. Psychology in Sports. St Petersburg, Russia: Peter; 2010.

11. Ilyin EP. Psychology of Individual Differences. St Petersburg, Russia: Peter: 2010.

12. Teplov BM. Selected Works, Vol 2. Moscow, Russia: Pedagogika; 1985.

13. Nebylitsyn VD. Fundamental Properties of the Human Nervous System. Moscow, Russia: Prosveshcheniye; 1966.

14. Drozdovsky AK, Nosach AR. The software "Prognoz 1.0". Moscow Rospatent Certificate 2002611802; 2002.

15. Drozdovsky AK. Age-related changes of neurodynamic characteristics of pupils. Proceedings of the 3rd Congress of the Russian Psychological Society, June 23-28, 2003, St Petersburg, Russia.

16. Drozdovsky AK. Neurodynamic characteristics of the professionals in various fields. Proceedings of the Scientific Conference "Psychology of 21st Century", April 22-24, 2004, St Petersburg, Russia.

17. Drozdovsky AK. Psychophysiological method of forecasting of volitional characteristics of professionals in various fields. Proceedings of the Scientific-Practical Conference "Ananyevsky readings-2008” University of St Petersburg, October 21-23, 2008, St Petersburg, Russia.

18. Drozdovsky AK. Neurodynamic characteristics of elite athletes. Proceedings of the Scientific Conference. SPBNIIFK, December 18-19, 2006, St Petersburg, Russia.
19. Drozdovsky AK, Gromova IA, Buylov PZ. Neurodynamic characteristics of paralympic athletes in different disciplines. International Scientific-Practical Conference "Innovative Technologies in the Sports Reserve”, July 2-3, 2010, St Petersburg, Russia.

20. Drozdovsky AK, Banayan AA. Neurodynamic characteristics of athletes in sailing, depending on the training level. International ScientificPractical Conference "Innovative Technologies in Top-level Sports", July 1-2, 2011, St Petersburg, Russia.

21. Drozdovsky AK, Banayan AA. Typological complex of the properties of the nervous system of sportsman in sailing. All-Russian Scientific and Practical Conference "Paralympic Movement in Russia on the Way to London: Problems and Solutions", October 24-25, 2011, St Petersburg, Russia.

22. Drozdovsky AK, Gromova IA, Zlydnev AA. About psychophysiological compatibility in Paralympic sport. All-Russian Scientific and Practical Conference "Paralympic Movement in Russia on the Way to Vancouver: Problems and Solutions”, October 20-21, 2009, St Petersburg, Russia.

23. Drozdovsky AK. Dependence of the degree of expression of personality traits on a combination of typological characteristics of the properties of the nervous system. Izvestia: Herzen Univ J Humanities Sci. 2006;5(23):131-135.

24. Drozdovsky AK. Study of the Connections of the Properties of the Nervous System with Psychodynamic Personality Characteristics $[\mathrm{PhD}$ thesis]. St Petersburg, Russia; 2008.

25. Golubeva EA. Ability. Personality. Individuality. Dubna, Russia: Fenix; 2005.

26. Merlin VS. Essay of the Temperament Theory. 2nd ed. Perm, Russia; Science. 1973.

27. Drozdovsky AK, Golub YV. The official registration of the software. Moscow Rospatent Certificate 2014612679; 2014.
Open Access Journal of Sports Medicine

\section{Publish your work in this journal}

Open Access Journal of Sports Medicine is an international, peer-reviewed, open access journal publishing original research, reports, reviews and commentaries on all areas of sports medicine. The manuscript management system is completely online and includes a very quick and fair peer-review system.

\section{Dovepress}

Visit http://www.dovepress.com/testimonials.php to read real quotes from published authors. 